\title{
Temporal transcriptomic response during arsenic stress in Herminiimonas arsenicoxydans
}

\author{
Jessica Cleiss-Arnold ${ }^{1}$, Sandrine Koechler ${ }^{1}$, Caroline Proux ${ }^{2}$, Marie-Laure Fardeau ${ }^{3}$, Marie-Agnès Dillies², \\ Jean-Yves Coppee ${ }^{2}$, Florence Arsène-Ploetze ${ }^{1}$, Philippe N Bertin ${ }^{{ }^{*}}$
}

\begin{abstract}
Background: Arsenic is present in numerous ecosystems and microorganisms have developed various mechanisms to live in such hostile environments. Herminiimonas arsenicoxydans, a bacterium isolated from arsenic contaminated sludge, has acquired remarkable capabilities to cope with arsenic. In particular our previous studies have suggested the existence of a temporal induction of arsenite oxidase, a key enzyme in arsenic metabolism, in the presence of $\mathrm{As}(\mathrm{III)}$.

Results: Microarrays were designed to compare gene transcription profiles under a temporal As(III) exposure. Transcriptome kinetic analysis demonstrated the existence of two phases in arsenic response. The expression of approximatively $14 \%$ of the whole genome was significantly affected by an As(III) early stress and $4 \%$ by an As(III) late exposure. The early response was characterized by arsenic resistance, oxidative stress, chaperone synthesis and sulfur metabolism. The late response was characterized by arsenic metabolism and associated mechanisms such as phosphate transport and motility. The major metabolic changes were confirmed by chemical, transcriptional, physiological and biochemical experiments. These early and late responses were defined as general stress response and specific response to As(III), respectively.

Conclusion: Gene expression patterns suggest that the exposure to As(III) induces an acute response to rapidly minimize the immediate effects of As(III). Upon a longer arsenic exposure, a broad metabolic response was induced. These data allowed to propose for the first time a kinetic model of the As(III) response in bacteria.
\end{abstract}

\section{Background}

Bacteria live in changing environments and are subjected to a variety of environnmental stresses such as $\mathrm{pH}$, temperature, osmolarity or heavy metals. Arsenic is found in numerous disturbed or natural ecosystems where it can exist in mutiple oxidation states, the most common being arsenite $\mathrm{As}(\mathrm{III})$ and arsenate $\mathrm{As}(\mathrm{V})[1]$. This metalloid is known to generate oxidative stress in cells by its capability to induce the formation of reactive oxygen species (ROS). The damages caused by ROS to lipids, proteins and DNA are likely to contribute to As toxicity $[2,3]$. In addition, one property of arsenite, which indicates that it behaves like a soft metal, consists in a high reactivity with sulphydryls groups and that

\footnotetext{
* Correspondence: philippe.bertin@unistra.fr

'UMR7156 Université de Strasbourg/CNRS, Génétique Moléculaire, Génomique et Microbiologie, Département Microorganismes, Génomes, Environnement, 28 rue Goethe, 67083 Strasbourg cedex, France Full list of author information is available at the end of the article
}

affects the activity of many proteins. Microorganisms have developed remarkable capabilities to cope with arsenic. The most common arsenic resistance mechanism depends on the presence on plasmid or chromosome of ars genes encoding proteins involved in the reduction and/or the efflux of the toxic element [4]. Nevertheless, other arsenic resistance mechanisms have been described, i.e. arsenite oxidation and arsenic methylation $[5,6]$. In addition, in various microbial species, arsenic stress is associated with arsenite oxidase activity, biofilm formation, motility, oxidative stress or sulfur assimilation $[7,8]$. For example, the biofilm development by Thiomonas arsenivorans has been described as a physical barrier decreasing As(III) access to sessile cells [9]. Remarkably, some organisms such as Rhizobium sp. NT-26, have evolved specific metabolic pathways allowing them to oxidize As(III) as an energy source $[10,11]$ or others are known to use $\mathrm{As}(\mathrm{V})$ in anaerobic respiration [12]. In the heterotrophic prokaryote Herminiimonas

\section{Biomed Central}


arsenicoxydans, genome sequencing revealed the presence of four ars operons involved in the reduction of $\mathrm{As}(\mathrm{V})$ to As(III) and of one aoxAB operon involved in the oxidation of the most toxic form, As(III) to the less toxic form $\mathrm{As}(\mathrm{V})$ [13]. In addition to this detoxification process, this bacterium exhibits positive chemotaxis and motility towards arsenic, and metalloid scavenging by exopolyssacharides.

The availability of the $H$. arsenicoxydans complete genome sequence offers an opportunity to study its physiology by functional genomic approaches [13]. Our previous transcriptomic studies have demonstrated that a large number of genes encoding proteins involved in oxidative stress, low affinity import of phosphate or DNA repair are induced after $15 \mathrm{~min}$ As(III) exposure. However, no variation was found in the genes coding for arsenite oxidase, a key enzyme in arsenic response [14] recently shown to be subjected to a complex regulation [15]. In addition, little is known regarding the kinetics of arsenic stress response in microorganisms. To address these processes, physiological analyses coupled with Western immunoblotting experiments and DNA microarrays were used to examine the temporal changes in transcriptome profiles during the transition from $\mathrm{As}(\mathrm{III})$ to $\mathrm{As}(\mathrm{V})$ species due to As(III) oxidation. Our work represents, to our knowledge, the first kinetic analysis of transcription pattern in bacteria exposed to arsenic, leading to propose a global model of arsenic response in $H$. arsenicoxydans.

\section{Results and Discussion}

\section{Characterization of arsenic oxidoreduction kinetics}

To study the oxidoreduction kinetic in $H$. arsenicoxydans, the two arsenic species (As(III) and As(V)) were quantified by HPLC-ICP-AES from filtered culture supernatants at several times after As(III) or As(V) induction (0, $15 \mathrm{~min}, 1,2,4,6$ and 8 hours) (Figure 1). In the presence of $\mathrm{As}(\mathrm{III})$ (Figure 1A), three distinct phases were observed: in phase A1 (early exposure: 0 to 4 hours), no oxidation was observed since arsenic was present as $100 \% \mathrm{As}(\mathrm{III})$. In phase A2, which corresponds to a partial oxidation of As(III) into As(V), both

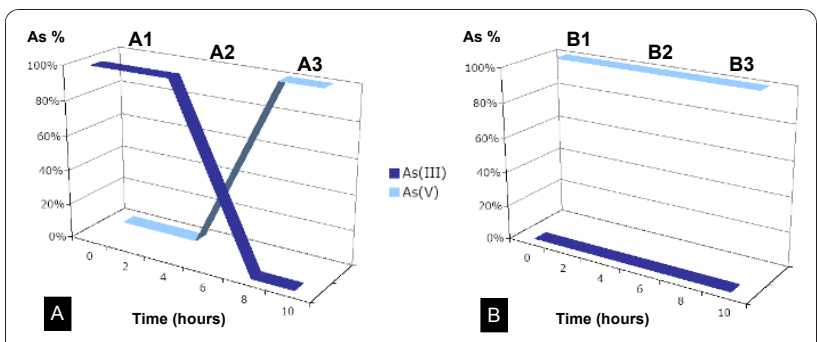

Figure 1 Temporal dynamics of arsenic oxidoreduction in H. arsenicoxydans. (A) Time course measurement of As(III) and As (V) species after As(III) exposure. species were present, a proportion of $50 \%$ As(III) and $50 \% \mathrm{As}(\mathrm{V})$ being observed after 6 hours. The transformation of $\mathrm{As}(\mathrm{III})$ into $\mathrm{As}(\mathrm{V})$ was complete after 8 hours (phase A3).

\section{Overview of transcriptome profiles}

To get insight into the mechanisms involved in arsenic response, including oxidoreduction processes, transcriptomic analyses were performed at different steps of the experimental time course. Cells were collected from cultures of $H$. arsenicoxydans induced 15 min (early), 6 hours (intermediary), 8 hours (late) or not with 0,66 $\mathrm{mM}$ As(III) (Figure 1A) or 13,3 mM As(V) (Figure 1B). These concentrations were choosen as they are far from $H$. arsenicoxydans MIC for $\mathrm{As}(\mathrm{III})$ or $\mathrm{As}(\mathrm{V})$, which is able to grow up to $5 \mathrm{mM}$ and $100 \mathrm{mM}$ of As(III) and As(V), respectively (Muller, 2007). Moreover, this concentration of As(III) had only a minor impact on growth rate and cells continued to divide immediately after its addition. Under $\mathrm{As}(\mathrm{V})$ stress, 128 genes were up-regulated and 107 genes were down-regulated in the early phase (B1) (7\% of the genome). In the late phase (B2) the number of genes up-regulated (239 genes) and down-regulated (161 genes) increased (12\% of the genome). Under As(III) stress, the proportion was inverted. The major shift in gene expression occured during the onset of the early phase (A1) with 214 genes upregulated and 245 genes down-regulated under As(III) stress. This represents approximatly $14 \%$ of the genes whose expression was significantly affected by As(III). As cell growth progressed further into the late phase (A3), the number of genes up-regulated (60 genes) and down-regulated (73 genes) decreased, representing $4 \%$ of the genome. The large number of genes responding to As(III), especially in the early phase, suggests a major remodelling of cellular physiology. In addition, oxidoreduction kinetic was only observed under As(III) stress (Figure 1A and 1B), suggesting that the Aox-dependent oxidation largely predominate the Ars-dependent reduction process. This study therefore focused on the As(III) response in $H$. arsenicoxydans.

\section{Hierachical clustering kinetics}

To classify the transcripts on the basis of their temporal dynamics after exposure to arsenite, we performed a hierarchical clustering with the ArrayMiner ${ }^{\bullet}$ software http://www.optimaldesign.com/ArrayMiner/ArrayMiner. htm. Genes were sorted into groups that exhibited similar transcription kinetics as cells transitioned from A1 to A3 phases. The set of genes regulated by As(III) shown in Figure 2 was classified into 20 clusters. The profiles similarity of those clusters enabled us to identify two major classes: 1 ) class I: (clusters $0,2,3,6,8,10$, $13,14,15$ and 19) containing genes whose expression 


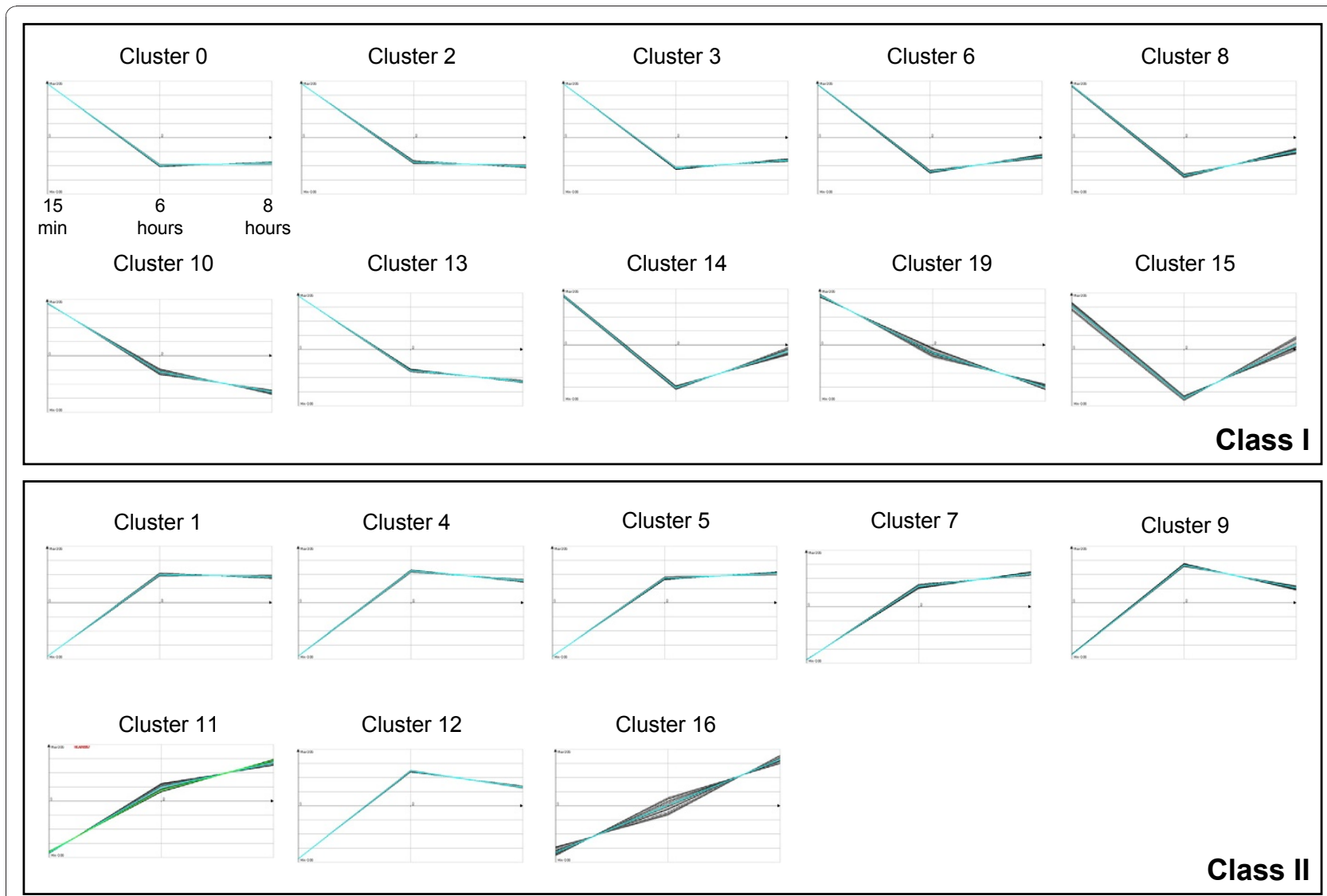

Figure 2 Patterns of gene expression changes during As(III) exposure. Expression graphs of the 20 clusters obtained by plotting the log 2 fold-change values (y-axis) at each of the three time points (x-axis). The average for all genes in each cluster is highligthed by a blue line. Class I and Class II contained genes whose expression levels gradually decreased or increased after the induction, respectively.

increased immediately after 15 min induction and decreased after 6 and 8 hours and class II: (clusters 1, 4, $5,7,9,11,12$ and 16) containing genes whose expression levels increased only after 6 and 8 hours induction. The product of each upregulated or downregulated gene by a fold change of two or more was identified to gain insight into the changes in physiology [Additional file 1: Supplemental Table S1]. Next, to examine how the two classes are distributed with regard to their functions, we further classified these genes according to the Gene Classification based on COG functional categories (Figure 3). The overall gene expression pattern suggests the existence of two major physiologic phases (early and late) during the adaptation to As(III) stress.

\section{i) Early phase}

Our microarray analysis highlighted a set of stress responsive genes whose transcription was early affected by As(III). This phase contained the early up-regulated genes whose expression levels gradually decreased after the induction (Class I) or down-regulated genes whose expression levels gradually increased after the induction (Class II).
First, $\sigma^{\mathrm{E}}$ and several genes encoding proteins involved in the synthesis of cell envelope components were down-regulated (Class II, Figure 3B (regulatory function, protein synthesis and fatty acid)) whereas genes encoding proteins involved in transport were up-regulated (Class I, Figure 3A (transport)). The bacterial envelope is a major defense against threats from the environment. Due to its crucial importance, the integrity of the cell envelope, including the presence of outer membrane proteins (OMP), is closely monitored to ensure its functionality. The $\sigma^{\mathrm{E}}$ system is the major pathway [16] required for proper folding of OMPs and their turnover [17], phospholipids and lipopolysaccharide (LPS) biosynthesis, signal transduction and the expression of inner and outer membrane proteins [18]. In Escherichia coli, the $\sigma^{\mathrm{E}}$ regulon is induced specifically in response to the unbalanced synthesis of outer membrane proteins [17] and to the misfolding of polypeptides that have been translocated across the cytoplasmic membrane [19]. Our results suggest that both the organization (lipoproteins, peptidoglycan and LPS) and the functioning (transport, signal transduction) of the bacterial 


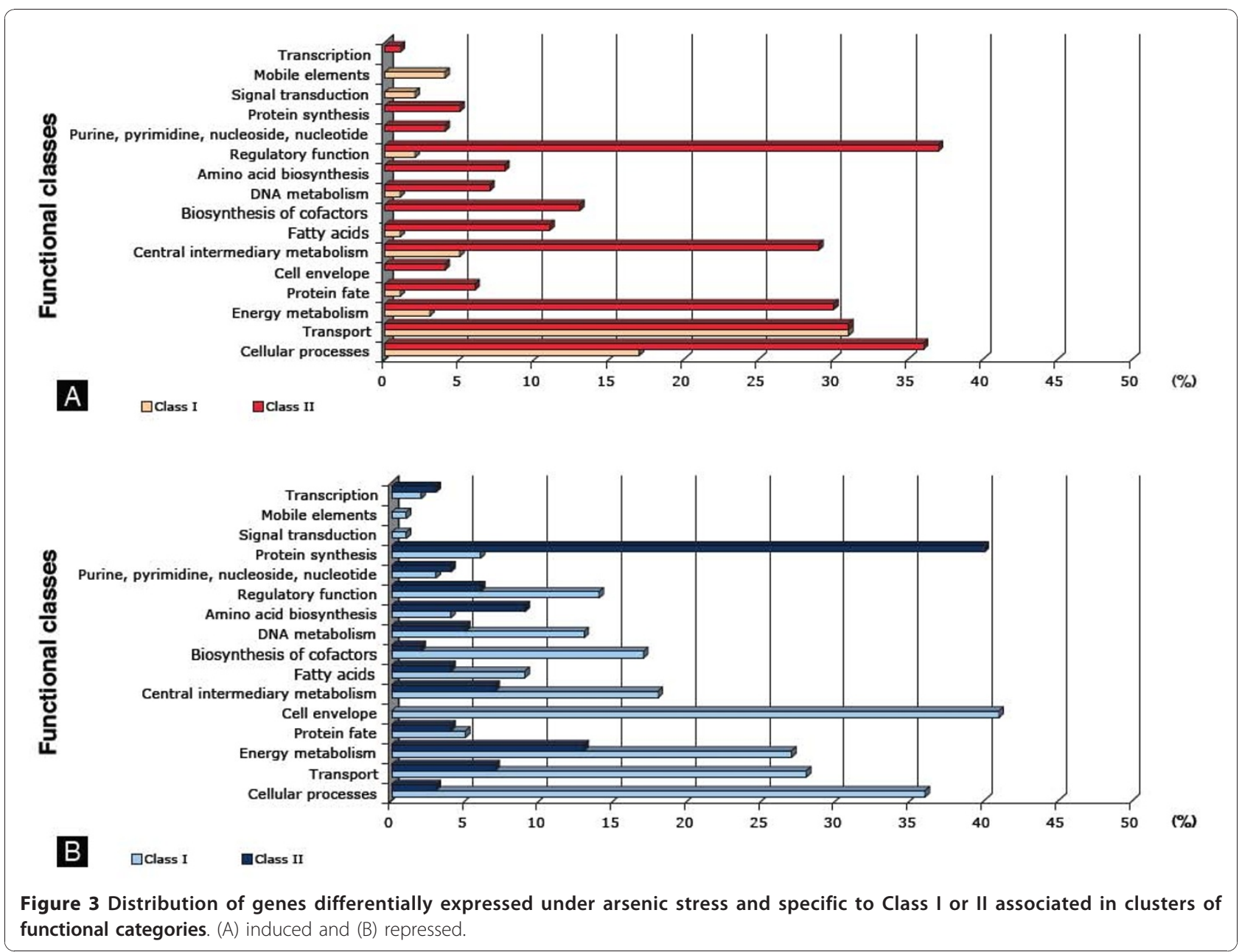

envelope may be changed in the early phase of the response to $\mathrm{As}(\mathrm{III})$.

Second, early As(III) stress strongly stimulated expression of genes encoding components of sulfur assimilation, sulfur oxidation and glutathione (GSH) biosynthesis pathways. In fact, mRNA levels of genes encoding all the enzymatic steps required for sulfate uptake, its conversion into cysteine and GSH were increased. The expression of these genes was induced about 3 to 22 fold after 15 min induction with As(III). The expression of some of these genes was down-regulated at 6 and 8 hours [Additional file 1: Supplemental Table S1, Class II]. In eukaryotic cells, As (III) exposure results in increased levels of reduced glutathione [20] and an As(III)-triglutathione complex has been found in human liver excreta [21], leading to the conclusion that GSH plays an important role in reducing As(III) toxicity. Most effects of arsenite result from its interaction with thiol groups of proteins, its iniophoretic properties and its ability to directly or indirectly generate free radicals and hence induce oxidative stress [22]. Microorganisms have therefore developed defense mechanisms that either keep the concentration of the $\mathrm{O}_{2}$-derived radicals at acceptable levels or repair oxidative damages. In our previous proteomic experiments, oxidative stress proteins, such as KatA and SodB, were shown to be induced in response to As(III) stress in H. arsenicoxydans [14]. Similarly, we observed in the present study a positive regulation of three genes $(\operatorname{sod} C, k a t A, a h p C)$ involved in the protection against oxidative stress. The $\operatorname{sod} C$ gene encodes the superoxide dismutase catalyzing the dismutation of the superoxide radical to $\mathrm{H}_{2} \mathrm{O}_{2}$, which is less toxic, and $\mathrm{O}_{2}$. In addition, $k a t A$ and $a h p C$ genes encoding a catalase and a peroxidase, respectively, are responsible for scarvenging endogenously produced $\mathrm{H}_{2} \mathrm{O}_{2}$. Finally, As(III) early exposure induced a glutaredoxin and various thioredoxin encoding transcripts [Additional file 1: Supplemental Table S1]. In $H$. arsenicoxydans the induction of genes encoding proteins involved in sulfate and GSH pathways suggests that GSH may play a key role in the cell defense against oxidative stress and metalloid toxicity by maintaining an intracellular reducing environment. GSH may detoxify arsenite by i) chelation and then removing of 
arsenite from the cell, ii) protection against oxidation caused by metals since GSH serves as the main redox buffer in the cell, and iii) binding to reactive sulfhydryl groups of proteins thereby protecting them from irreversible metalloid binding and/or oxidative damages [23]. Thioredoxin is believed to serve as a cellular antioxidant by maintaining the intracellular redox state, which is greatly influenced by the presence or absence of intracellular ROS, by reducing disulfide bonds produced by various oxidants and by interacting with proteins by direct association or thiol reactivity. Glutaredoxin is also known as a thioltransferase and like thioredoxin possesses an active center disulphide bond. Finally, arsenic could indirectly produce ROS by inactivating catalytic iron-sulfur clusters of enzymes as it has been shown for enzymes of the deshydratase family in E. coli in the presence of copper. In this organism, iron-sulfur clusters are the primary targets of copper and the resulting damages lead to the release of iron atoms in the cell and the generation of hydroxyl radicals [24]. All these cellular activities (GSH, catalase, peroxidase and thioredoxin-related) are thought to be part of a general set of reactions involved in the direct or indirect response to $\mathrm{As}(\mathrm{III})$-mediated production of reactive oxygen species in $H$. arsenicoxydans.

Third, the adaptive responses of bacteria to sudden environmental changes, usually involve the induction of many major heat shock proteins MHSPs, including chaperones, proteases, transcriptional regulators and other structural proteins. As(III) induced the expression of several genes encoding MHSPs [Additional file 1: Supplemental Table S1]. The MHSPs play a role in repairing and preventing damages caused by an accumulation of unfolded proteins resulting from diverse environmental stresses. In agreement with this, our microarray data showed that As(III) early exposure induced the transcription of two uspA genes that might be involved in protecting bacterial cells against As(III) stress. The protein UspA has previously shown to be induced by As (III) [14]. The expression of the universal stress protein A (UspA) is known to be induced by a large variety of stress conditions [25], our results show that these conditions include As(III).

Finally, arsenic resistance in $H$. arsenicoxydans is partially mediated by proteins encoded by three different ars operons and one aox operon [13]. The clusters of ars genes encode an ArsR regulator, an As(III) extrusion pump ArsB/Acr3, an ArsH putative flavoprotein and one or two arsenate reductases ArsC. One of the loci contains an Acr3-type transporter, the others associate an ArsB-type transporter with ArsC reductases. ArsC is an enzyme that reduces $\mathrm{As}(\mathrm{V})$ to $\mathrm{As}(\mathrm{III})$ which can be pumped out by the ArsB or Acr3 membrane proteins. Both $a c r 3$ and $\operatorname{ars} B$ genes were induced in the presence of As(III). However, Acr3 mRNAs were only detected in
15 min As(III) exposed cells, which demonstrates that Acr3 is specific to the early response. Remarkably, the arsenite oxidase genes were not induced in early phase. The lack of induction of the aox genes is in agreement with the detection by HPLC-IC-AES of $100 \%$ As(III) (Figure 1).

\section{ii) Late phase}

This phase contains genes whose expression levels gradually increased (class II) or decreased (class I), after arsenic exposure. Multiple genes of cellular processes, cell envelope and metabolism (energy, intermediary, DNA...) were highly downregulated in class I (Figure 3B). Class II was characterized by the induction of several functional categories, i.e. genes involved in metabolism, regulatory functions and cellular processes (Figure 3A). These genes are suggested to be specific for the late response to As(III).

First, $H$. arsenicoxydans reacted to a late As(III) exposure by activating genes involved in the transport and assimilation of phosphate as well as other phosphorous compounds [Additional file 1: Supplemental Table S1]. Indeed, after late exposure, phosphate specific transporter (Pst) and phosphate inorganic transporter (Pit) were induced. Although we cannot exclude that the various genes involved in phosphate uptake were strongly induced because of a partial depletion of phophate in the medium, this induction could also result from the accumulation of $\mathrm{As}(\mathrm{V})$. Indeed, $\mathrm{As}(\mathrm{V})$ produced by the oxidation of As(III), which only occurred in late phase (Figure 1), may compete with phosphate because of their structural similarity. So, $H$. arsenicoxydans may preferentially transport phosphate via the specific Pst phosphate transport system rather than the Pit general transport mechanism, in order to reduce the entry of As (V). These observations suggest that a complex regulation of the pst and pit operons allows $H$. arsenicoxydans to maintain its intracellular phosphate level despite the accumulation of As $(\mathrm{V})$. This further supports our previous hypothesis on the physiological link between arsenic and phosphate metabolism [13].

Second, genes involved in chemotactic machinery and flagellum assembly were up-regulated after late exposure to As(III). Our results from the microarray experiments during exposure to As(III) combined to previous observations [13] clearly demonstrate that the chemotactic response is induced by As(III). In $H$. arsenicoxydans the flagellar machinery is organized in a mixed peritrichous/ polar cascade which is most probably synthesized through sequential hierarchy of gene activation events initiated by the expression of the master transcriptional regulator FlhDC [13]. The microarray results strongly suggest that motility is gradually induced in response to As(III) in $H$. arsenicoxydans.

Finally, the aox operon was induced after late exposure. The aox operon contains aoxA encoding the small 
subunit of arsenite oxidase, $a \circ x B$ encoding the large subunit, $a o x C$ encoding a nitroreductase and $a o x D$ encoding a cytochrome c552. The aoxRS operon is involved in the regulation of aox $A B C D$ operon [15]. All of them were induced by late As(III) stress [Additional file 1: Supplemental Table S1, Class II], which strongly suggests that arsenite oxidase activity is specific to late exposure.

\section{Transcriptional and physiological analysis of the major metabolic changes}

Our microarray data suggest that several genes play a major role in the transition from the absence of As(III) to early or late arsenic exposure. To confirm this hypothesis, chemical, transcriptional, physiological and biochemical experiments were performed.

First, to further support the involvement of glutathione synthesis and sulfate metabolism in early As(III) response (early phase) in $H$. arsenicoxydans, we performed quantitative RT-PCR experiments. Transcripts abundance of gloA and soxC were compared to two internal controls, i.e the putative RNA methyltransferase gene and the peptide deformylase gene, in cultures challenged $15 \mathrm{~min}$, 8 hours or not by As(III). The expression of soxC and gloA mRNA was increased by a 312 and 7 fold factor, respectively, after $15 \mathrm{~min}$ As(III) exposure. No such induction was observed in late exposure.

To address the possible role of As(III) in the GSH pathway, the total content of GSH was measured. The pool of GSH increased after $15 \mathrm{~min}$ ( 3 fold) and further rose over time ( 5 fold after 6 hours). After 8 hours the level remained unchanged, as compared with 6 hours. These observations suggest that the accumulation of GSH in response to $\mathrm{As}(\mathrm{III})$ was specific to the early phase. In addition, although we did not observed any change in the extracellular concentration of sulfate, genes encoding sulfate uptake were up-regulated after $15 \mathrm{~min}$ and down regulated after 6 and 8 hours [Additional file 1: Supplemental Table S1]. Moreover, genes involved in the sulfur oxidation pathway, i.e. $\operatorname{sox} C$, $\operatorname{sox} D$, were also induced [Additional file 1: Supplemental Table S1]. A similar induction of enzymes involved in sulfur metabolism has already been shown under oxidative stress in Pseudomonas aeruginosa [26]. Oxidative stress enzymes, i.e. thioredoxin and superoxide dismutase, are known to be implicated in sulfur assimilation and metabolism [27,28]. Our results suggest that the intracellular concentration of different species of sulfur compounds is altered in $H$. arsenicoxydans under arsenic stress, demonstrating for the first time that sulfur metabolism is also impaired in response to arsenic stress.

On the other hand, to confirm the oxidative stress response resulting from arsenic exposure, peroxidase activity was measured from cultures induced or not, 15 min, 6, 8 hours with As(III). The activity was induced
5 fold after $15 \mathrm{~min}$ and remained unchanged after late exposure. This observation demonstrates that peroxidase activity is also specific to the early exposure to As(III).

Second, the induction of arsenite oxidase activity in the late phase was demonstrated in this study (Figure 1). The oxidation was complete after 8 hours exposed cells. On agar plate, the activity was detectable after 48 hours growth in presence of As(III), by a silver nitrate staining test (data not shown). The accumulation of arsenite oxidase was tested by Western immunoblotting experiments with anti-AoxB antibodies. AoxB was detected in protein extract from cells induced for 6 and 8 hours. In contrast, no protein was detected after 15 min induction (Figure 4) which explains the lack of aox gene expression after $15 \mathrm{~min}$ in the presence of As(III) observed in a previous study [14]. Arsenite oxidase activity is therefore specific to late exposure to $\mathrm{As}(\mathrm{III})$ in $H$. arsenicoxydans. In addition, in As(III) non exposed cultures of some bacteria, As(III) oxidation did not occur until cultures reached stationary phase, as suggested in Agrobacterium tumefaciens [29], indicating that quorum sensing is involved in the regulation of As(III) oxidation. However, in $H$. arsenicoxydans, no significant induction of genes involved in quorum sensing was observed in the time course experiment.

Similarly, to support the effect of arsenic on flagellar motility and phosphate transport in the late phase, the transcript abundance of $f l i C$ and $p s t S b$ was measured. pstSb mRNAs increased by a 455 fold factor after 8 hours As(III) exposure but no such induction was observed in early exposure. Remarkably, fliC was induced by a 14 and 11 fold change after $15 \mathrm{~min}$ and 8 hours, respectively.

The motility of $H$. arsenicoxydans was analyzed in the presence and the absence of As(III). As shown in Figure 5 a swarming diameter of $10 \mathrm{~mm}$ was measured for cells incubated 48 hours whithout arsenic on the semisolid medium. In the presence of As(III), cells were

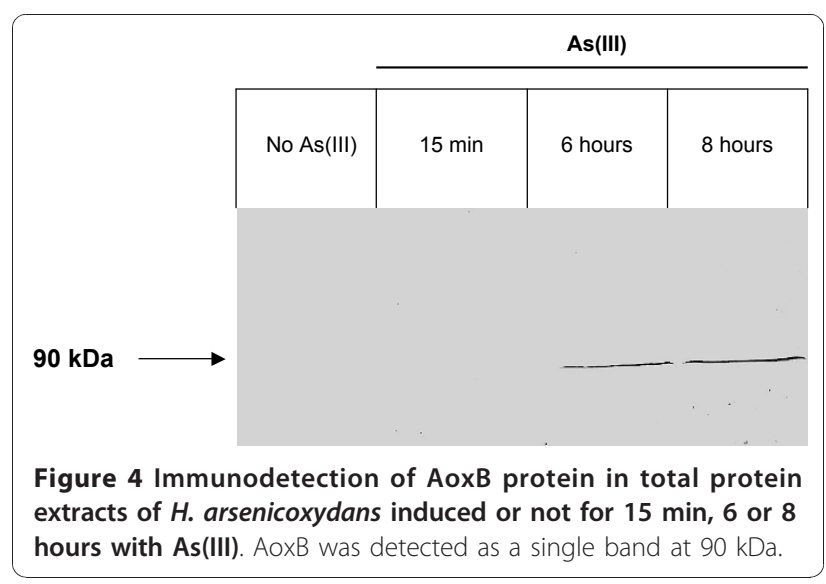




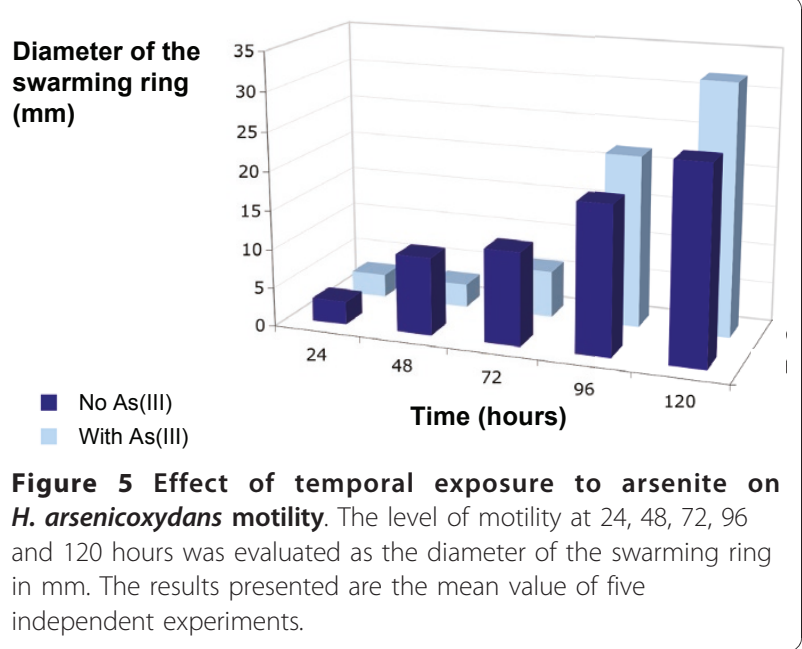

mobile on semi-solid medium only after 72 hours incubation $(12 \mathrm{~mm})$, which corresponds to the late phase in liquid medium. These results suggest that the presence of As(III) delays cell motility. However, no significant difference in the expression of flagellar genes was observed between early and late exposure [Additional file 1: Supplemental Table S1]. Moreover, the expression of $\operatorname{mot} A$ and $\operatorname{mot} B$ genes, encoding proteins responsible for the rotary activity of flagellum motor [30], was not affected by early or late exposure to As(III). These observations clearly demonstrate that the flagellum biosynthesis was not altered in response to As(III), unlike its functioning. In $H$. arsenicoxydans, the rotation of this flagellar appendange is driven by a sodium motive force [13]. Because the arsenite oxidase is known to be a periplamic enzyme, in agreement with Western immunoblotting experiments on cell fractions (data not shown), and the oxidation of arsenite releases four protons [31], we proposed that arsenite oxidase activity may indirectly increase motility. Indeed, a $\mathrm{Na}^{+} / \mathrm{H}^{+}$antiporter has been shown to be involved in A. tumefaciens As(III) oxidation [32]. In $H$. arsenicoxydans, the genome exploration revealed the possible synthesis of such a $\mathrm{Na}^{+} / \mathrm{H}^{+}$transporter. The protons released from arsenite oxidation may thus extrude $\mathrm{Na}^{+}$through this antiporter and generate the electron potential for the $\mathrm{Na}^{+}$-driven flagellar motor, as described in the differentiation of flagellar system of Vibrio alginolyticus [33]. This hypothesis could explain how arsenite oxidase contributes to the motility of $H$. arsenicoxydans after As(III) late exposure.

\section{Conclusion}

Many microorganisms have acquired the capacity to survive in the presence of toxic metals or metalloids by inducing the expression of resistance genes. The specific nature of these resistance mechanisms is the result of a cleverly designed genetic circuit that is tightly controlled by regulatory proteins. However, the multiple physiological responses induced by arsenite stress in $H$. arsenicoxydans are not exclusively associated with the expression of classical arsenic resistance operons. Indeed, in this study we demonstrated that the adaptation to As(III) is characterized by an early and a late response. A highly sophisticated regulatory network may thus modulate the expression of genes in response to arsenic. These effects are mediated in part through the activation or repression of mRNA transcripts by DNA-binding proteins and signal transduction systems, such as ArsR, AoxRS and others. All these transcriptomic observations are summarized in a kinetic and metabolic model (Figure 6).

The early response is characterized by the induction of genes involved in general stress. First, GSH is a protagonist of the primary cellular responses to As(III). The genes encoding enzymes involved in sulfate uptake (A), sulfur oxidation (B), cysteine synthesis (C) leading to cysteine containing proteins and their conversion in GSH (D) were induced. As(III)-exposed cells may thus channel a large part of the assimilated sulfur into GSH for metal chelation, cellular redox buffering and possibly also protein glutathionylation. As(III) may react with $\mathrm{GSH}$ to form an $\mathrm{As}(\mathrm{SG})_{3}$ complex (E). Interactions of these As-thiol group non specific complexes with molecular oxygen lead to the formation of reactive oxygen species such as $\mathrm{H}_{2} \mathrm{O}_{2}$, resulting in oxidative stress within the cell. The As(III) is extruded by ArsB or Acr3 (F) and Acr3 induction was demonstrated to be specific to early exposure. The mechanism proposed here is in agreement with the observations made with HPLC-ICP-AES, showing that no oxidation occurred in early As(III) stress and only As(III) species was present.

The late response was characterized by the induction of genes specific for arsenic. Indeed, the GSH response is downregulated (A) and the transcripts encoding arsenic resistance (B), especially arsenite oxidase and its regulation $(\operatorname{aox} R S)(\mathrm{C}, \mathrm{D})$, and associated mechanisms such as phosphate uptake (E) and flagellum biosynthesis (F) were upregulated. The arsenite oxidase catalyses the oxidation of $\mathrm{As}(\mathrm{III})$ in $\mathrm{As}(\mathrm{V})$ (D). As(V) may directly enter the cell via the Pst or Pit transporter (E), where it is reduced to $A s(\mathrm{III})$ by the arsenate reductase and extruded into the periplasm via ArsB (F). Then As(V) produced by the oxidation of As(III) is extruded out of the cell $(\mathrm{G})$. The mechanism proposed here for the late response to $\mathrm{As}(\mathrm{III})$ is in agreement with the oxidoreduction kinetics and underlies the links between arsenic, phosphate and motility.

In this study, we demonstrated that the detoxification and metabolism processes are gradually expressed in 


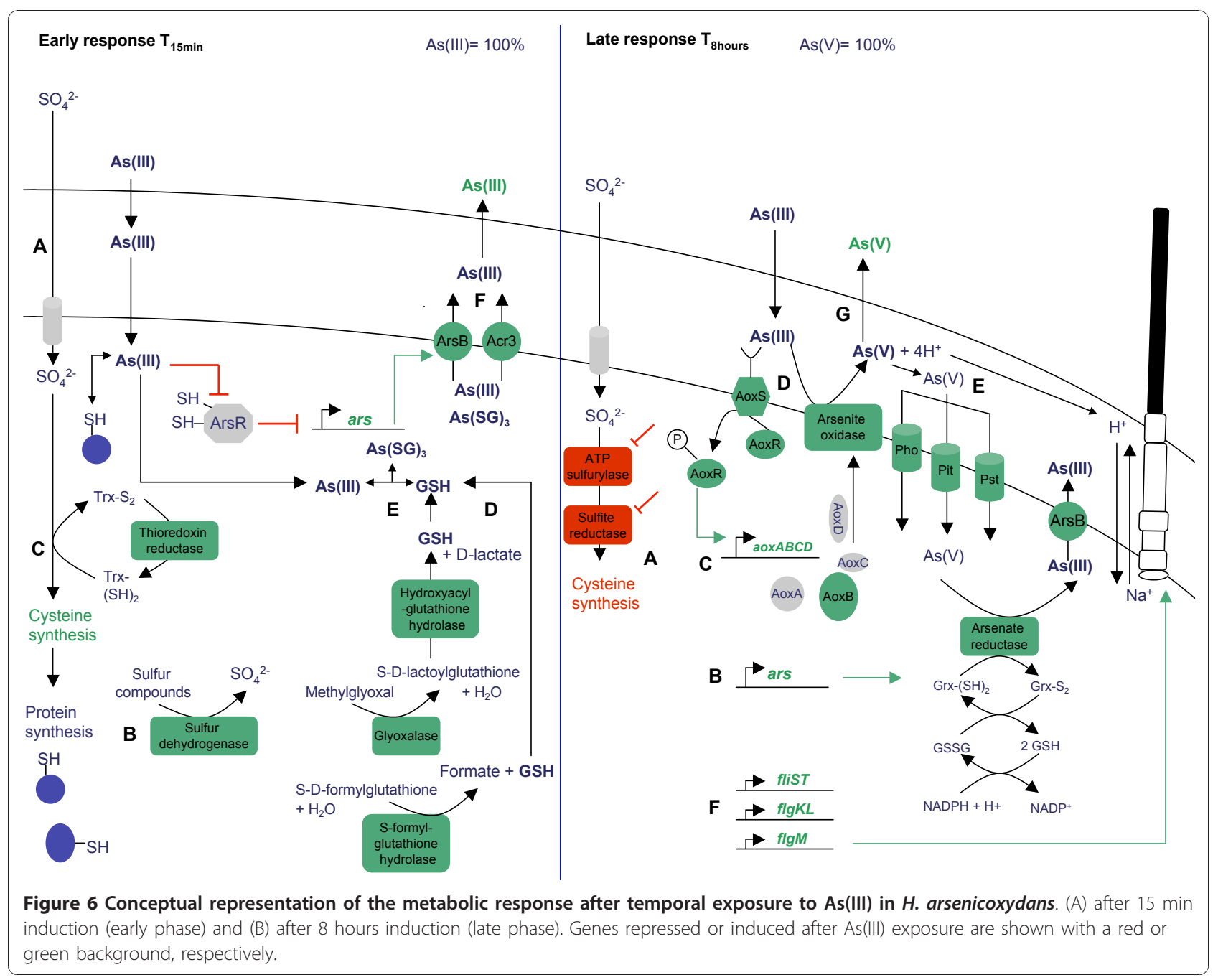

$H$. arsenicoxydans to adapt to arsenic-rich environments. In bacteria, the response to $\mathrm{As}(\mathrm{III})$ seems therefore to be characterized by a stereotypic just-in-time transcription of specific metabolic pathways, resulting in a two-step response.

\section{Methods}

\section{Bacterial strains and growth media}

$H$. arsenicoxydans ULPAs1 was grown in a chemically defined medium (CDM), supplemented by $2 \%$ agar when required [34]. Tryptone swarm plates containing CDM supplemented with 1\% Bacto-Tryptone and 0.25\% agar were used to assess bacterial motility.

\section{Arsenic speciation and sulfate determination}

$H$. arsenicoxydans was grown in CDM medium and cultures were induced when required by addition of $0.66 \mathrm{mM} \mathrm{As}$ (III) for $15 \mathrm{~min}, 1$ hour, 2, 4, 6 or 8 hours. Similarly, cultures were induced or not for $15 \mathrm{~min}$, 6 hours, 8 hours with $13.3 \mathrm{mM}$ As(V). Culture supernatants were filtered through sterile $0,22 \mu \mathrm{m}$ pore size filters (VWR). Arsenic species were separated by highperformance liquid chromatography (HPLC) and quantified by inductively coupled plasma-atomic emission spectrometry (ICP-AES), as previously described [35]. Sulfate extracellular concentration was determined by ion chromatography (IC) using a Metrohm Compact IC 761 system. The column used was a MetrosepA SUPP 1-250 $(4.6+250 \mathrm{~mm})$ with an eluent concentration of $3 \mathrm{mM}$ sodium carbonate.

\section{Peroxidase and total glutathione assay}

Peroxidase activity and total glutathione were measured from serially diluted $\left(10^{0}-10^{-3}\right) 48$ hours-old cultures of $H$. arsenicoxydans exposed or not to As(III). The peroxidase activity was determined using the Amplex Red Hydrogen Peroxide Assay kit (Invitrogen) and the total glutathione concentration was measured using the colorimetric glutahione detection kit (PromoKine). This assay was performed according to the protocol provided by the manufacturer. 
Preparation of protein extracts, SDS-PAGE separation Protein extracts and Western immunoblotting experiments were performed as described previously in Koechler et al. [15]

\section{RNA extraction}

Strains were grown at $25^{\circ} \mathrm{C}$ for 24 hours $(\mathrm{OD}=0,15$ at $600 \mathrm{~nm}$, corresponding to log-phase cells) and cultures were induced or not by addition of $0,66 \mathrm{mM} \mathrm{As(III)} \mathrm{for}$ 15 min, 6 hours or 8 hours before extraction. After 8 hours induction the OD was checked and was still corresponding to log-phase cells (OD $=0,56)$. Similarly, 13,3 $\mathrm{mM} \mathrm{As}(\mathrm{V})$ were added or not to a 24 hours cultures during $15 \mathrm{~min}, 6$ hours or 8 hours. Samples were harvested and stored at $-80^{\circ} \mathrm{C}$. RNA were extracted as previously described [14]. After extraction procedure, RNA integrity was checked by electrophoregram analysis on a BioAnalyser (Agilent) and total RNA concentration was determined spectrophotometrically with a Nanodrop.

\section{Microarrays and data analysis}

Microarrays containing 60-mer oligonucleotides for all predicted $H$. arsenicoxydans genes http://www. genoscope.cns.fr/agc/mage/arsenoscope were used, as previously described [14]. Briefly, total RNA $(5 \mu \mathrm{g})$ was reverse transcribed and indirectly labelled and next hybridized to the arrays. Three distinct biological RNA samples were prepared from each growth condition at different time after induction with $\mathrm{As}(\mathrm{III})$ or $\mathrm{As}(\mathrm{V})(0$ min and after 15 min, 6 hours or 8 hours) and labelled either by $\mathrm{Cy} 3$ or $\mathrm{Cy} 5$ in a dye-swap design. Microarray data were deposited in ArrayExpress (accession E-MEXP-2809). Scanning, data normalization and statistical analysis was performed as described [14]. Genes showing a valid $p$-value and a more than two-fold decreased or increased expression were considered as differentially expressed between the conditions tested and were retained for further study.

Clustering analysis was performed using ArrayMiner http://www.optimaldesign.com/ V. 5.3.4 with the Gaussian clustering and Pearson correlation options selected. The data table included $\log 2$ ratios at three different time points ( $15 \mathrm{~min}, 6$ and 8 hours) with $\mathrm{t}=0$ being a reference. 2349 genes were significantly up- or downregulated in at least one of the three time points. The number of classes has to be tuned prior to the run. It was chosen to 20, as it appeared to provide homogeneous profiles within classes with a reasonable number of unclassified genes.

\section{Quantitative real time PCR}

Quantitative PCR experiments were performed as described by Koechler et al. [15], with the following modification of thermocycling conditions: $5 \mathrm{~min}$ at $95^{\circ} \mathrm{C}$ and 40 cycles of $15 \mathrm{~s}$ at $95^{\circ} \mathrm{C}, 15 \mathrm{~s}$ at $60^{\circ} \mathrm{C}$ and $1 \mathrm{~min}$ at $72^{\circ} \mathrm{C}$. Two biological replicates (independent cultures) and two quantitative PCR replicates were performed in each experience. Amplification products were designed in order to obtain less than $175 \mathrm{bp}$ fragments. The pairs of primers used are listed in Additional file 1: Supplemental Table S1.

\section{Additional material}

Additional file 1: Supplemental table S1. Selected genes differentially expressed after 15 min or 8 hours arsenite stress. Genes are classified according to their class and cluster. Class I contains genes whose expression increased after 15 min induction and decreased after 8 hours. Class II contains genes whoses expression increased only after 8 hours induction.

\section{Acknowledgements}

JCA was supported by a grant from the French Ministry of Education and Research. Financial support came from the Centre National de la Recherche Scientifique, the Agence Nationale de la Recherche (ANR 07-BLAN-0118 project) and the Université de Strasbourg. This work was done in the frame of the Groupement de Recherche (GDR2909-CNRS): « Métabolisme de l'Arsenic chez les Micro-organismes».

\section{Author details}

'UMR7156 Université de Strasbourg/CNRS, Génétique Moléculaire, Génomique et Microbiologie, Département Microorganismes, Génomes, Environnement, 28 rue Goethe, 67083 Strasbourg cedex, France. ${ }^{2}$ Plateforme technologique Puces à ADN, Institut Pasteur, 28 rue du Dr. Roux, 75724 Paris cedex 15, France. ${ }^{3}$ IRD Laboratoire de Microbiologie, ESIL, 163 Avenue de Luminy 13288 Marseille cedex 9, France.

\section{Authors' contributions}

JCA and SK wrote the manuscript. JCA performed the microarray data and clustering analysis, Western immunoblotting and motility experiments, arsenic, peroxidase and total glutathione determination. SK carried out the quantitative PCR experiments. CP, MAD and JYC conceived and performed the transcriptomic and clustering experiments. MLF determined the sulfate concentration. FP and PB helped to analyse the data and critically revised the manuscript. PB coordinated and conceived the study. All authors read and approved the final manuscript.

Received: 13 July 2010 Accepted: 17 December 2010 Published: 17 December 2010

\section{References}

1. Cullen WR, Reimer KJ: Arsenic speciation in the environment. Chemical Reviews 1989, 89(4):713-764.

2. Abernathy CO, Liu YP, Longfellow D, Aposhian HV, Beck B, Fowler B, Goyer R, Menzer R, Rossman T, Thompson C, et al: Meeting on Arsenic: Health Effects, Mechanisms of Actions, and Research Issues, Hunt Valley, Maryland, 22-24 September 1997. Environmental Health Perspectives 1999, 107(7):593-597.

3. Mandal BK, Suzuki KT: Arsenic round the world: A review. Talanta 2002, 58(1):201-235

4. Rosen BP: Biochemistry of arsenic detoxification. FEBS Letters 2002, 529(1):86-92

5. Muller D, Lièvremont D, Simeonova DD, Hubert JC, Lett MC: Arsenite oxidase aox genes from a metal-resistant beta-proteobacterium. Journal of Bacteriology 2003, 185(1):135-141.

6. Qin J, Rosen BP, Zhang Y, Wang G, Franke S, Rensing C: Arsenic detoxification and evolution of trimethylarsine gas by a microbial arsenite S-adenosylmethionine methyltransferase. Proceedings of the 
National Academy of Sciences of the United States of America 2006, 103(7):2075-2080.

7. Thorsen M, Lagniel G, Kristiansson E, Junot C, Nerman O, Labarre J, Tamos MJ: Quantitative transcriptome, proteome, and sulfur metabolite profiling of the Saccharomyces cerevisiae response to arsenite. Physiological Genomics 2007, 30(1):35-43.

8. Parvatiyar K, Alsabbagh EM, Ochsner UA, Stegemeyer MA, Smulian AG Hwang SH, Jackson CR, McDermott TR, Hassett DJ: Global analysis of cellular factors and responses involved in Pseudomonas aeruginosa resistance to arsenite. Journal of Bacteriology 2005, 187(14):4853-4864.

9. Michel C, Jean M, Coulon S, Dictor MC, Delorme F, Morin D, Garrido F: Biofilms of As(III)-oxidising bacteria: formation and activity studies for bioremediation process development. Applied Microbiology and Biotechnology 2007, 77(2):457-467.

10. Santini JM, Sly LI, Schnagl RD, Macy JM: A new chemolithoautotrophic arsenite-oxidizing bacterium isolated from a gold mine: Phylogenetic physiological, and preliminary biochemical studies. Applied and Environmental Microbiology 2000, 66(1):92-97.

11. Santini JM, Kappler U, Ward SA, Honeychurch MJ, vanden Hoven RN, Bernhardt PV: The NT-26 cytochrome c552 and its role in arsenite oxidation. Biochimica et Biophysica Acta - Bioenergetics 2007, 1767(2):189-196.

12. Stolz JF, Oremland RS: Bacterial respiration of arsenic and selenium. FEMS Microbiology Reviews 1999, 23(5):615-627.

13. Muller D, Medigue C, Koechler S, Barbe V, Barakat M, Talla E, Bonnefoy V, Krin E, Arsene-Ploetze F, Carapito C, et al: A tale of two oxidation states: bacterial colonization of arsenic-rich environments. PLoS genetics 2007, 3(4).

14. Weiss S, Carapito C, Cleiss J, Koechler S, Turlin E, Coppee JY, Heymann M, Kugler V, Stauffert M, Cruveiller S, et al: Enhanced structural and functional genome elucidation of the arsenite-oxidizing strain Herminiimonas arsenicoxydans by proteomics data. Biochimie 2009, 91(2):192-203.

15. Koechler S, Cleiss-Arnold J, Proux C, Sismeiro O, Dillies M-A, GoulhenChollet F, Hommais F, Lièvremont D, Arsène-Ploetze D, Coppée J-Y, et al: Multiple controls affect arsenite oxidase gene expression in Herminiimonas arsenicoxydans. BMC Microbiology 2010, 10:53.

16. Brooks BE, Buchanan SK: Signaling mechanisms for activation of extracytoplasmic function (ECF) sigma factors. Biochimica et Biophysica Acta - Biomembranes 2008, 1778(9):1930-1945.

17. Mecsas J, Rouviere PE, Erickson JW, Donohue TJ, Gross CA: The activity of $\sigma(\mathrm{E})$, an Escherichia coli heat-inducible $\sigma$-factor, is modulated by expression of outer membrane proteins. Genes and Development 1993 $7(12$ B):2618-2628

18. Rezuchova B, Miticka H, Homerova D, Roberts M, Kormanec J: New members of the Escherichia coli $\sigma \mathrm{E}$ regulon identified by a two-plasmid system. FEMS Microbiology Letters 2003, 225(1):1-7.

19. Missiakas D, Betton JM, Raina S: New components of protein folding in extracytoplasmic compartments of Escherichia coli SurA, FkpA and Skp/ OmpH. Molecular Microbiology 1996, 21(4):871-884.

20. Ochi T: Arsenic compound-induced increases in glutathione levels in cultured Chinese hamster V79 cells and mechanisms associated with changes in $\gamma$-glutamylcysteine synthetase activity, cystine uptake and utilization of cysteine. Archives of Toxicology 1997, 71(12):730-740.

21. Kala SV, Neely MW, Kala G, Prater Cl, Atwood DW, Rice JS, Lieberman MW: The MRP2/CMOAT transporter and arsenic-glutathione complex formation are required for biliary excretion of arsenic. Journal of Biological Chemistry 2000, 275(43):33404-33408.

22. Bernstam L, Nriagu J: Molecular aspects of arsenic stress. Journal of Toxicology and Environmental Health - Part B: Critical Reviews 2000 3(4):293-322

23. Pompella A, Visvikis A, Paolicchi A, De Tata V, Casini AF: The changing faces of glutathione, a cellular protagonist. Biochemical Pharmacology 2003, 66(8):1499-1503

24. Macomber L, Imlay JA: The iron-sulfur clusters of dehydratases are primary intracellular targets of copper toxicity. Proceedings of the National Academy of Sciences of the United States of America 2009, 106(20):8344-8349

25. Kvint K, Nachin L, Diez A, Nyström T: The bacterial universal stress protein: Function and regulation. Current Opinion in Microbiology 2003, 6(2):140-145.
26. Salunkhe $P$, Töpfer T, Buer J, Tümmler B: Genome-wide transcriptional profiling of the steady-state response of Pseudomonas aeruginosa to hydrogen peroxide. Journal of Bacteriology 2005, 187(8):2565-2572.

27. Zeller T, Klug G: Thioredoxins in bacteria: Functions in oxidative stress response and regulation of thioredoxin genes. Naturwissenschaften 2006, 93(6):259-266.

28. Imlay JA: Cellular defenses against superoxide and hydrogen peroxide. Annual Review of Biochemestry 2008, 77:755-776.

29. Kashyap DR, Botero LM, Franck WL, Hassett DJ, McDermott TR: Complex regulation of arsenite oxidation in Agrobacterium tumefaciens. Journal of Bacteriology 2006, 188(3):1081-1088.

30. Chevance FFV, Hughes KT: Coordinating assembly of a bacterial macromolecular machine. Nature Reviews Microbiology 2008, 6(6):455-465.

31. Ellis PJ, Conrads T, Hille R, Kuhn P: Crystal structure of the $100 \mathrm{kDa}$ arsenite oxidase from Alcaligenes faecalis in two crystal forms at $1.64 \hat{\mathrm{A}}$ and 2.03 Â. Structure 2001, 9(2):125-132.

32. Kashyap DR, Botero LM, Lehr C, Hassett DJ, McDermott TR: A Na+:H+ antiporter and a molybdate transporter are essential for arsenite oxidation in Agrobacterium tumefaciens. Journal of Bacteriology 2006, 188(4):1577-1584.

33. Yorimitsu T, Homma M: Na+-driven flagellar motor of Vibrio. Biochimica et Biophysica Acta - Bioenergetics 2001, 1505(1):82-93.

34. Muller $\mathrm{D}$, Simeonova DD, Riegel $\mathrm{P}$, Mangenot $\mathrm{S}$, Koechler $\mathrm{S}$, Lièvremont $\mathrm{D}$, Bertin PN, Lett MC: Herminiimonas arsenicoxydans sp. nov., a metalloresistant bacterium. International Journal of Systematic and Evolutionary Microbiology 2006, 56(8):1765-1769.

35. Muller D, Lievremont D, Simeonova DD, Hubert JC, Lett MC: Arsenite oxidase aox genes from a metal-resistant beta-proteobacterium. Journal of Bacteriology 2003, 185(1):135-141.

doi:10.1186/1471-2164-11-709

Cite this article as: Cleiss-Arnold et al:: Temporal transcriptomic response during arsenic stress in Herminiimonas arsenicoxydans. BMC Genomics 2010 11:709.

\section{Submit your next manuscript to BioMed Central and take full advantage of:}

- Convenient online submission

- Thorough peer review

- No space constraints or color figure charges

- Immediate publication on acceptance

- Inclusion in PubMed, CAS, Scopus and Google Scholar

- Research which is freely available for redistribution

Submit your manuscript at www.biomedcentral.com/submit
Ciomed Central 